\title{
A Survey of Cognitive and Psychological Factors Effective on Travelling
}

\author{
Morteza Izadi ${ }^{1}$, Seyed Omid Seyed Ahmadinejad ${ }^{1, *}$ \\ 1. Health Research Center, Baqiyatallah University of Medical Sciences, Tehran, Iran
}

*Corresponding Author: Seyed Omid Seyed Ahmadinejad, MD, Health Research Center, Baqiyatallah University of Medical Sciences, Tehran, Iran

Email: sosahmadinejad@gmail.com

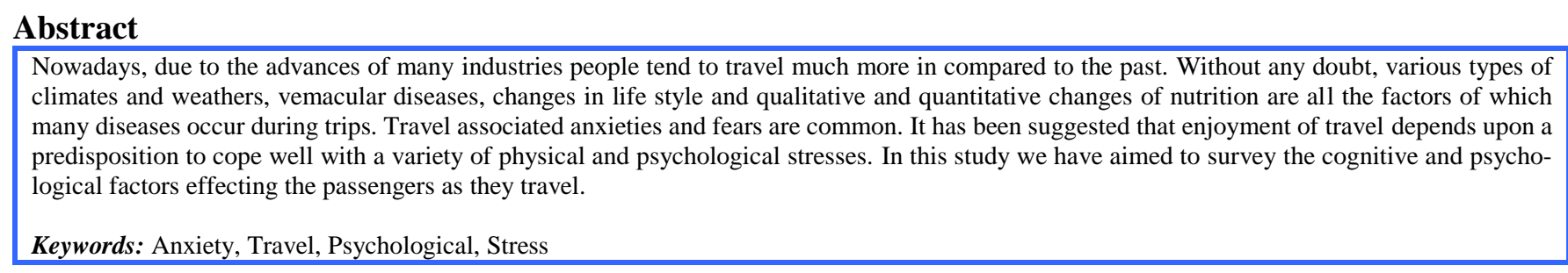

Article History: Received: 2 Apr 2015; Revised: 25 May 2015; Accepted: 7 Jun 2015

Cite this article as: Izadi M, Seyed Ahmadinejad SO. A survey of cognitive and psychological factors effective on travelling. Int J Travel Med Glob Health. 2015;3(2):7580 .

\section{Anxiety and Travelling}

Unfortunately nowadays, anxiety has become a growing issue and of course its symptoms cause a vast range of problems [1]. Anxiety is a multidimensional concept that appears at different levels such as physical, cognitive, emotional, and interpersonal. Theoretically speaking, anxiety can be induced by any stimulator (social psychological stressors), while the individual is not even aware of such influences [2,3]. Anxiety, indeed, is an early warning process and tells the individual about an immediate hazard and to prepare to deal with the hazard. As the psychological mode of anxiety is highly disturbing, people cannot stand it in long runs and usually a coping mechanism or other defensive mechanisms are adopted by the person to deal with long-term anxieties. According to studies, men, the youth, and richer social classes experience less anxiety compared to women, the elderly, and social classes with less income [3].

Anxiety and its effect on tourism is a poorly surveyed area of study. Symptoms of neuroticism that are developed during long journeys is widely examined in psychiatry literature. Temporary paranoid reaction is a disease introduced by Flinn [4] and Sing [5], which has to do with the change of environment, encountering with unknown environments, isolation, and lack of activity. Zislin [6] introduced this condition as traveling paranoia and argued that in most cases, it is developed during train traveling featured with moderate changes regarding time zones. However, no mood disorder has been reported regarding this form of traveling.

Miller and Zarcone [7] studied 49 patients in mental hospitals who had been in the San Francisco Airport seven years ago on average. In addition to paranoia symptoms, the subjects showed anxiety and mania symptoms. The authors believed that the symptoms had been developed before landing. A recent study by Cheng and Hungg [8] showed that about 10 passengers needed emergency psychiatric interventions after landing in the Taipei Int'l Airport. Hiatt and Spurlick [9] emphasized that long flights are featured with sudden changes in the environment that in some cases in- duce severe critical problems for the passengers. They recommended providing necessary psychological treatments in case needed. Shapiro [10] studied 359 patients referred to psychological check in Kennedy Int'l Airport and found that about $38 \%$ were paranoid schizophrenic, $36.4 \%$ were schizophrenic and other cases, $2.2 \%$ suffered from several depression, $2.7 \%$ had psychological depression reactions, $13 \%$ had OBS including alcohol addiction and reaction to drugs, and about $5 \%$ had nervous disorders. Shapiro [10] introduced several factors effective on the development of neuroticism including traveling, cultural shock after landing, and jet leg. Many studies have worked on the role of culture in the development of nervous disorders throughout traveling [11]. On the other hand, the development of nations and public transportation facilities have made the facilities a good option to meet the growing demand for traveling [12]. However, with an increase in the number of people who use public transportation the probability of anxiety and overcrowding increases [12]. One challenge ahead of urban planners and decision makers is to provide a way to solve resistance against using public transportation for traveling [12]. Anxiety is an emotion, and thus, each person has a unique anxiety [13]. Anxiety might be due to ambiguities as to environmental and cognitive variables [13] and among them, anxieties caused by traveling are common [14]. Transportation conditions are among the causing factors. Several studies have dealt with the experience of traveling using different means of transportation. Bor [15] introduced a general viewpoint of psychological aspects of air travels in particular and how people (passengers and crews) are influenced by them.

Stradling et al. [16] studied public bus systems in Edinburgh, Scotland to gain a better perception of using public bus systems. They named eight factors that reduce the popularity of public bus systems: sense of insecurity, more tendency to walking and cycling, problems with the services, undesirable stimulation, preferring using personal car, costs, poor performance, uncomfortable experience, and self-image. 
Li [17] studied terms and experiences of urban travels using specifications of transportation (time and frequency of transportation), districts, environment of the traveling, and hope. It is notable that the anxiety caused by traveling was not studied by Li. The study specifically focused on the waiting time at stations, boarding the train, and riding the train and mainly described public transportation. Few studies have examined anxiety among train travelers. However, there are few studies, which have focused on specific areas such as access to station [18]. Cox et al. [19] studied passenger accumulation at train stations and anxiety onboard. There might be considerable differences between traveling experiences based on personal characteristics such as gender, age, and physical abilities.

\section{Depression and Travelling}

What threatens mental, physical, and social health of people is "depression," which has troubled many different societies [20]. Depression is one of the most common mental disorders and about $15 \%$ of depressed patients may even commit suicide [21].

There is a firm recommendation by psychologists and psychiatrists for attenuating mental-social pressures, improving the environment and avoiding unwanted conditions, traveling to new areas and temporary stays in remote villages and cities, forgetting negative stimulations of routine life, and regaining liveliness [22]. In addition to soothing mental pressures, travelling increases the thinking and mental power of one to tolerate different viewpoints through inducing considerable changes in cognitive fields and feedback systems. It also prevents the accumulation of mental pressures and disorientation as well as bad experiences [23].

\section{Depression Treatment}

Early diagnosis and treatment of depression is effective on the term and severity of depression [24]. Anti-depression interventions can be classified into medicine and non-medicine treatments. The effectiveness of each one of these methods have been the subject of several studies. In the case of acute depression, anti-depression medicines are the best option [24]. Occupational therapy and cognitive-behavioral psychological treatments and analytical treatments in some occasions are recommended [25]. In the case of mild depression, depressurizing and removing stressors by, for instance, breaking large tasks to small steps, determining the priority for some tasks, doing sports, participating in religious, social, and family events, avoiding alcoholic drinks, avoiding high-fat diets, trying to be optimistic, watching fun and comedy movies, traveling, and participating in useful activities can improve one's feelings [25].

However, studies on mutual effects of traveling and depression have led to different conclusions.

There is a considerable overlap between depression and jet lag disorders; both are syndromes of impatience, lack of enough energy, indifference, reluctance, sleep disorders, and disorientation along with an increase of sensitiveness, anxiety and psychophysical disorders [26]. Tec [27] reported one case of intrinsic depression following jet lag. Jauhar and Weller [28] studied 186 patients receiving medical services in the Hitro Airport and showed that the depression of the subjects was due to sudden and large changes in time zones. Comparisons showed that the depression severity was higher when people travel from east to west. The results showed that $25 \%$ of the patients were sick before takeoff and $48 \%$ were sick immediately after reaching the destination. Among the subject, 70\% stated records of mental diseases. These results indicate that time zone changes accelerate mental diseases in vulnerable individuals [29].

Findings by Juahar and Weller [30] in Honolulu showed that 30 passengers of a flight with small time zone changes received psychological checks. All of them were hospitalized within 10 days after landing and during the same period symptoms of jet lag, which were strong enough to influence mental conditions, were also shown by the subjects. Twenty of the patients without an experience of travelling were selected as the control group. As recommended by the results, passengers who traveled eastward showed higher mania symptoms compared to the control group; while the passengers to west showed severer symptoms of depression comparing to the control group.

Although, many of the patients in these studies were schizophrenic, it is not easy to show relevance of mental attack and jet lag. Oyewumi [31] reported reappearance of schizophrenic disorder after flying over the Atlantic eastward despite interventions with clozapine.

\section{How Traveling Influences Behavior?}

Some of the airlines' customers are those traveling abroad to spend their holidays and alleviate stress. However, the mere act of traveling is a stressful activity [32]. Some stressors might seem trivial such as dealing with a short delay; although, they may induce severe emotional reactions. Failure of the flight attendants and airlines' representatives to give convincible explanation for the inconveniences adds to the complicacy of the situation. Leaving the well-known and secure environment increases vulnerability to psychological pains and hardships and also increases the probability of encountering the variety of health problems [33].

Travelling and air travel in particular may cause depression, anxiety, nervous attacks, and even madness in vulnerable people. Encountering problems and inconveniences is common in the course of travelling and in the case of air travel, people are not prepared to deal with some of the variety of inconveniences such as delay, takeoff problems, and troubles in the course of flying [33].

Although, many engineering advances have turned flying into a fast, interesting, and amazing experience, people need to take specific measures to deal with physical and mental demands of traveling [34]. Even experienced travelers, apparently, experience "emotional pressure" while they are in airplanes, trains, or cruises. This might be due to a wide range of emotional factors including leaving beloved relatives, anxiety and concerns as to the safety of the travel, lack of attachments, concerns as to break of routines, fear of attachments to strangers, and seemingly small issues such as quality of foods or losing baggage [34]. Additionally, people have unique phobia about specific ways of travelling such as aerophobia, claustrophobia, and these problems might even emerge before boarding [32, 33].

\section{How Traveling Influences Behavior?}

Whether directly or indirectly, air traveling influences peoples' behaviors and somehow makes it hard to satisfy the passengers. However, apparently, few studies have been done on passengers' needs and rights [35].

According to DSM-IV-TR, aerophobia is a specific position depended phobia and it is defined as a severe and long-term fear. People suffering from this cannot convince themselves 
to travel by airplane, although, they know their fears are baseless [36].

About 10 to $20 \%$ of Americans suffer from aerophobia and about $20 \%$ of them depend on alcohol and other pain killers to overcome their phobia. Because of phobia many lose their jobs, financial opportunities, or suffer social shame each year [36].

There are several treatment methods proposed to help these individuals. Until the 1960s, the majority of treatment methods emphasized on unconscious ego, which was renown as long-term explorative psychodynamic. The most common treatment was called exposure therapy [37].

Another method was to force patients to face their fears and therefore needed access to phobic motivator. There are reports of implementation of such treatments, however, in the case of aerophobia, therapists had small opportunities to make patients face their fears. Nowadays, such techniques rely on new technologies such as virtual reality [37].

The term virtual reality was proposed by Jaron Liner three decades ago. The technique relies on computer technology to create a $3 \mathrm{D}$ world in which the patient can see, hear, and feel the phobic elements [38].

The effectiveness of virtual reality on acrophobia was studied by Ratbam et al. [39] and Butla et al. [40] on clithrophobia, and by Vald and Taylor [41] on amaxophobia.

Kaplan (2000) studied 40 individuals with aerophobia using virtual reality for treatment and reported that 31 individuals managed to attenuate the phobia. These results are consistent with studies by Richard Veklin (2000) on aerophobia of a female teacher at the age of 47 . Virtual reality was considerably effective on attenuating subject's phobia [42].

Helen et al. (2007) studied 4 subjects and reported attenuation of aerophobia of the subject using virtual reality [43]. Virtual reality, compared with traditional treatment, brings in notable advantages and usages. Preparing actual environment can be too costly as the patients and therapists, in the case of aerophobia, have to book a flight and actually experience the flight [52]. In addition, planning and programming such activities is not easy not mentioning security and confidentiality concerns of the treatment. Virtual reality solves all these issues [44].

Interesting environments, not concerning about the failure of the practices, and creating the actual feelings of flying are the positive features of virtual reality environments. In fact, aerophobics prefer dealing with threatening environments and virtual reality is a far better choice as it enables the patients to feed confident, tough, and capable of interacting with the environment. Because of this, even 4 treatment sessions can be considerably effective in reducing anxiety [53-55, 45].

On the other hand, virtual reality helps the patient to remember their past so that they can review their fears and recognize their emotions. In fact, the patient tests the reality and practices skills, emotional excitement, self-scrutiny, and real world perceptions through recreating the past and learning about ambiguous aspects of their experiences with emotions $[46,47]$.

Using virtual reality, helps the patient determine situations that induces more anxiety and reduces the influence of such situations by repeating them. The patients are let to encounter their fears with no need to visualize phobic situations. Several senses of the patients are motivated, so that there is no need for mental visualizations [42].

Despite short academic history of virtual reality, it is one of the effective techniques to treat aerophobia. Still the short history indicates demands for more studies on the technique [42, 43].

Beckham et al. [48] examined a researcher-design checklist including stress-inoculation training using control group settings. The proposed treatment was very cost effective as after a 50min introduction by the therapist, patients could continue a 4 weeks treatment course. Treatments based on researcher-designed checklists at different scales are far better than having no intervention strategies. A behavioristic post-test showed that $82 \%$ of the intervention group and $36 \%$ of the non-intervention group managed to fly.

\section{Jet Lag Syndrome and Travelling What is Jet Lag?}

The development of airplanes made air travels between continents a common practice in the late 20th century. Along with the development of the airline industries, new problems such as jet lag appeared as new challenges [49]. Passengers, nowadays, can easily fly from the East to the West. However, these passengers usually suffer from a series of problems during the first few days after arriving to the destination. For instance, athletes are not able to perform well for a few days when they travel from one continent to another [49].

Jet lag is a physiological condition that is rooted in problems with the 24 hrs body clock. The disorder can be caused by long-range flights or rotating shift jobs. Air travels over more than two time zones usually induce physical, psychological, and emotional symptoms in the passengers [50]. When the sleep-wake cycle and circadian rhythm are interrupted, people experience sleep disorders. As recommended by studies, more than $90 \%$ of long-range air travels suffer from jet lag [50].

The critical point is that airline staff, who presumably should be immune to jet lag, even show the symptoms. The number of time zones traveled by the individual determines how many days it takes to accustom to the new environment. As shown by studies, physical and physiologic trends may need two weeks at most to accustom themselves to the new time zone [48].

Jet lag is more evident in the elderly, passengers who travel more time zones, and nervous and stressed people. In addition, flying eastward induces more intense symptoms compared with westward flights. In former cases one travels to a place where time lags behind their expectation and the individual prefers to stay awake rather than sleeping $[49,50]$. Jet lag does not develop in those traveling by ship or car and it is the high speed of air traveling that does not allow the individual to accustom to the new time zone. Naturally, people experience little problem to accustom themselves to 1 to 2 time zone changes which usually happens in road and sea traveling [51].

Jet lag is the inability of the physiological clock to adjust itself with the new time zone. Nerves take light and darkness signals from the eyes to the time center in the hypothalamus and the body realizes what the time is. Therefore, when an individual witnesses dawn or sunset few hours earlier or later than what he/she expected, hypothalamus prepares the body for activities for which the body is not ready and then jet lag appears [51].

Cortisol and melatonin circadian secretions controls the natural clock and rhythm. In the first few mornings of the new time zone, the body lacks cortisol and the passenger notices the problem when he/she wakes up. Maximum and mini- 
mum body temperature occurs in 3-5pm and 3-5am respectively. Time zone shift breaks this rhythm and it takes a few days to reset the body clock [52].

It takes 4 to 7 days for the body to adjust its temperature. Human body shows different reactions to fast time shifts. Different body hormones and electrolytes have different circadian rhythm adjustment rates and while serotonin rhythms are fast in readjusting, cortisol and potassium need more time to readjust. Sleep rhythm changes considerably, insomnia is not evident at the first night and then intensifies in the next few nights [49].

Readjustment with the local time takes longer in eastward flights; that is, people experience less intense problems after westward flights. The reason is that eastward flights compresses the time cycles and westward expands the cycles, which is closer to the body clock cycle. Symptoms of the jet lag and their intensity depends on the direction of the flight and the number of time zone shifts [53].

There are other factors effective in the development of jet lag such as air pressure and height changes as the airplane ascends, long-term flights during which the passengers have to sit, and dry air inside the airplane [51, 53].

Another factor is the reduction in the melatonin hormone secretion. The hormone tells the brain that it is time to sleep; however, the normal secretion of the hormone changes when the circadian cycle changes [52].

\section{Circadian Rhythm}

The circadian rhythm control in the mammal is constituted of a pair of hypothalamic cores called SCN [54]. Light information is directly sent from the sub-cortical to the cores through the retinohypotalamic path. Non-light information, in order to balance the light information, is also supplied from the thalamus and midbrain. All data are collected and processed into oscillating messages to the brain and other parts of the body [54].

\section{Sleep-wake Cycle Control}

Among the proposed models to describe sleep-wake cycle, the two-stage model has encountered with general agreements.

Two-stage model: process $\mathrm{S}$ : according to this process, sleep is the result of the accumulation of sleep needs after the last sleep. The process functions like a sand clock that determines sleep and awake time cycles.

Process C: the process controls sleep awake cycle based on circadian cycle and dictates the time of any activity [55].

\section{Sleep Structure Temporary Control}

Thanks to new technologies such as polysomnography (including electroencephalography (EEG), electromyography (EMG), and electrooculography (EOG)), sleep behaviors, patterns, and disorders can be easily determined in sleep clinics [55].

Scientific evidences recommend that the short wave sleep (SWS) phase at the first stage of non-REM-sleep can be used to estimate the $S$ process. It is said that with an increase of the awake time, the length of this phase increases logarithmically. On the other hand, the central body temperature is another useful index to evaluate the $\mathrm{C}$ process; as the desire to sleep increases, along with the decrease of body temperature and vice versa. It is not clear which one of these processes has the highest effect on the sleep and awake cycle; however, apparently the $\mathrm{C}$ process is more important.
Behavioral and physiological circadian rhythms of mammals are set genetically and controlled by suprachiasmatic core; additionally the cells' peripheral oscillators are set by circadian cycle. There are two gens in charge of setting the cycle, which function based on the number of oscillations determined by heredity [56].

Taking into account that the suprachiasmatic core of hypothalamus sets central body clock, the cock is actually set based on analyzing the received signals from the neural cells of the retina. The rhythm is a bit longer than $24 \mathrm{hrs}$; however, being under continuous influence of the environmental changes, especially the day-night cycle, and other factors such as temperature, humidity, and so on. The body clock is adjusted by the external factor; although the process of adjustment is slow [56].

All body cells may have molecular elements that enable internal tissues and organs of the body to create an environmental clock. The central clock is an environmental clock that may control non-light environmental signals. Although molecular mechanism coordinates central and environmental clocks, the factors to reach this coordination (light, nutrition, and physical activity) are not thoroughly known [57].

Circadian cycles have a critical role in the development of the hormonal and behavioral rhythms such as sleep-wake and body temperature cycles. Living organisms adapt to the repeating day-night cycles and most of the body hormone follow the cycle, which is not exactly a $24 \mathrm{hrs}$ cycle. All chemical elements of the body follow ascend and descent periods, which interact with the other cycles of body. Temperature, sleep, thyroid hormone, growth hormone, adrenal hormone and the like follow a cyclic behavior. There is a direct link between retina and a specific part of the brain that controls the secretion of hormones. Artificial light can induce similar effects like that of sun light at smaller scales $[55,56]$.

People who are not aware of the exact time, develop a $24 \mathrm{hrs}$ cycle when they have access to sun light. The cycle is started by sun light and justifies the difference between $14 \mathrm{hrs}$ day and $24 \mathrm{hrs}$ natural rhythm. Circadian clock of cells reacts to different day and night terms and let the organism coordinate with the changes of the environment [56].

The natural clock is in charge of sleeping at night and remaining awake during the day.

Interrupting the cycle can cause jet lag, psychological diseases, and even some sorts of cancer. The actual mechanism is not clear yet, however, specific hormones with circadian secretion patterns (e.g. cortisol and melatonin) probably influence the cycle and natural clock. Cortisol is secreted by hypothalamus-pituitary gland-adrenal in response to stress and based on a circadian cycle. The hormone, normally, follows a maximum/minimum rhythm at sunset and at night. Disorder in the cortisol secretion order leads to disorders in the circadian cycles for few days $[55,56]$.

Recent studies have shown that body cells have their own biological clock; for instance, the liver cells are prepared for digestion at specific hours of the day. Hormone secretion patterns determine maximum and minimum brain activity called seiglman [57].

Circadian cycle (21-26hrs) influences our behavior, physiology, and emotions. The cycle is controlled by the suprachiasmatic core and as evidences show, the core is comprised of different parts and one of them processes light information. The information is, then, sent to a mediatory 
group and this group transfers the information to the peripheral group. This hierarchy of processing creates a time delay in coordinating the body with the environment [58].

Therefore, by removing environmental changes and their effects on circadian rhythm, one can stay awake longer. This intervention can help the process of adjusting with new time zones during long-term flights from east to west [57, 58].

In general, by travelling several time zones in few hours, the harmony between environmental time changes and the natural clock is terminated. In order to solve this problem, the body clock should be readjusted with the new environment, which may take several days sometimes up to 2 weeks.

Internal organs such as the lungs need more time to harmonize themselves with the suprachiasmatic core and the organs which are more sensitive to light, harmonize faster. Studies have reported that changes in the oxygen demand rhythm without an energy source reference induces changes in circadian shifts in peripheral tissues especially the liver $[57,58]$.

\section{Symptoms of Jet Lag}

Among the symptoms of jet lag insomnia, temper, constipation, diarrhea, dehydration, headache, sensitivity, nausea, sweating, and loss of memory can be mentioned out. Studies have shown that more than $90 \%$ of long-term flight passengers suffer from jet lag and $94 \%$ reported their symptoms quite disturbing. In addition, $90 \%$ experienced fatigue, $53 \%$ reported disorientation, $73 \%$ reported insomnia, 94\% reported dizziness and lack of energy, 90\% reported bad sleep, $32 \%$ reported body limb swelling, and $70 \%$ reported ear, nose, and throat problems during the first 5 days after landing [51].

Dehydration is mainly due to dry air inside the airplane that may cause headaches, dried skin, and rhinitis stimulation. Flight stress, fatigue, and headaches are more severe during landings and take offs. According to WHO, jet lag is the cause of intensification of microbial diarrhea due to water and food contamination. About $20-50 \%$ of air travelers suffer from these problems. Age, alcohol, and hypoxia intensify the symptom [59].

\section{How to Relieve Symptoms of Jet Lag?}

The proposed solutions to control or treat the disorder are based on accelerating the adjustment of circadian rhythm with the new environment. The process of control and treatment is much easier (about 1 to 3 days) when the flight has been over 3 time zones [60].

\section{Non-medicine Treatments}

The treatment can be implemented by the crews and the passenger without limitation [61].

\section{Light}

Light intensity of the environment is a key element in the treatment. The individual might be asked to stay in front of 10000lux light source (50 times brighter than normal room light) for 30min. Light-therapy is a good method; however, those suffering from eye diseases should consult with a physician beforehand.

Travelers to east, experience increase of body temperature and insomnia. Therefore, they should avoid light during these hours.
Travelers to west, experience delay in the decrease of body temperature at night and an increase of body temperature in the morning.

Enough water and non-alcoholic and non- caffeine drinks can help reduce the effects of jet lag. Food diet is an easy and not expensive option to modify the symptoms. Having physical activities such as walking, stretching, doing aerobics while sitting can also help. Doing such exercises helps travelers to accelerate the body clock readjustment. Food diet is also helpful for those with changing work shifts [62]. Anti-jet lag program relies on time signals such as meal time, dawn and sunset, and rest and activity periods. The program tries to reset time signals and initiates the program few days before traveling to accelerate adjustments with the new time zone by changing the amount and type of food. This is done in order to force the body to function according to the circadian cycle of the destination time zone. The program is recommended for those traveling over more than 3 time zones and workers with changing work shifts [63].

The human body naturally needs one day for every time zone change in a flight. However, with the help of the special food programs, the travelers can adjust with the new time zone in only one day. A study on 186 passengers who traveled 9 time zones and used the food program showed that the symptoms reduced 7.5 times after eastward travel and 16.2times after westward travel. The juvenile, for instance, barely need jet lad food program and can adjust rapidly with the new time zone.

\section{Medicine Treatments}

Taking sleep pills during and after flight is not usually recommended. However, some travelers by overnight flights are satisfied with taking the pills; although they need medical consultation. The consultation is highly recommended in the case of using melatonin as a sleep medicine [64]. As suggested by studies, although, melatonin is not generally recommended as a sleep medicine, its effect in avoiding jet lag symptoms is undeniable. Travelers from west to east can take melatonin in the afternoon and convince themselves that night comes sooner, and travelers from east to west can use melatonin in the morning and stay awake a bit longer. At any rate, there is no standard protocol in this regard. According to a general principle, flight crews are banned from using any medicine combination (even OTC combination) unless aerospace medicine experts permits so [64].

\section{References}

1. Jameson JP, Blank MB. Diagnosis and treatment of depression and anxiety in rural and nonrural primary care: national survey results. Psychiatr Serv. 2010;61(6):624-7.

2. Rizzolo CL, Taylor JE, Cerciello RL. Anxiety and anxiety-related disorders in the adolescent population: an overview of diagnosis and treatment. Adolesc Med State Art Rev. 2009;20(1):188-202, x-xi.

3. Valente SM. Diagnosis and treatment of panic disorder and generalized anxiety in primary care. Nurse Pract. 1996;21(8):26, 32-4, 378 , passim.

4. Flinn DE. Transient psychotic reactions during travel. Am J Psychiatry. 1962;119:173-4

5. Singh $\mathrm{H}$. A case of psychosis precipitated by confinement in long distance travel by train. Am J Psychiatry. 1961;117:936-7.

6. Zislin S. Ocherki Klinichishoy Psychiatrii (in Russian). Moscow: Medicina, 1965

7. Miller WB, Zarcone V. Psychiatric behavior disorders at an international airport. Arch Environ Health. 1968;17(3):360-5.

8. Cheng WS, Hung C. Three years' experience in passenger medical care at Taipei International Airport. Aerosp Med. 1974;45(1):82-3.

9. Hiatt CC, Spurlock RE. Geographical flight and its relation to crisis theory. Am J Orthopsychiatry. 1970;40(1):53-7. 
10. Shapiro S. A study of psychiatric syndromes manifested at an international airport. Compr Psychiatry. 1976;17(3):453-6.

11. Bar-El I, Witztum E, Kalian M, Brom D. Psychiatric hospitalization of tourists in Jerusalem. Compr Psychiatry. 1991;32(3):238-44.

12. Waterhouse J, Reilly T, Edwards B. The stress of travel. J Sports Sci. 2004;22(10):946-65.

13. Bandelow B, Lichte T, Rudolf S, Wiltink J, E Beutel M. The diagnosis of and treatment recommendations for anxiety disorders. Dtsch Arztebl Int. 2014;111(27-28):473-80.

14. McIntosh IB, Swanson V, Power KG, Raeside F, Dempster C. Anxiety and health problems related to air travel. J Travel Med. 1998;5(4):198-204.

15. Bor R. Psychological factors in airline passenger and crew behaviour: a clinical overview. Travel Med Infect Dis. 2007;5(4):207-16.

16. Stradling S, Carreno M, Rye T, Noble A. Passenger perceptions and the ideal urban bus journey experience. Transp Policy. 2007;14(4):283-92.

17. Li YW. Evaluating the urban commute experience: a time perception approach. J Public Transp. 2003;6(4),41-67.

18. Cheng YH. Exploring passenger anxiety associated with train travel. Transportation. 2010;37:875-96.

19. Cox T, Houdmont J, Griffiths A. Rail passenger crowding, stress, health and safety in Britain. Transp Res. 2006;40(3):244-58.

20. Galovski TE, Blanchard EB, Malta LS, Freidenberg BM. The psychophysiology of aggressive drivers: comparison to non-aggressive drivers and pre- to post-treatment change following a cognitive-behavioural treatment. Behaviour Research \& Therapy. 2003;41:1055-67.

21. Gaynes BN. Identifying difficult-to-treat depression: differential diagnosis, subtypes, and comorbidities. J Clin Psychiatry. 2009;70(Suppl 6):10-5.

22. Jacob KS. The diagnosis and management of depression and anxiety in primary care: the need for a different framework. Postgrad Med J. 2006;82(974):836-9.

23. Greenberg J, Tesfazion AA, Robinson CS. Screening, diagnosis, and treatment of depression. Mil Med. 2012;177(8 Suppl):60-6.

24. Khouzam HR. The diagnosis and treatment of depression in the geriatric population. Compr Ther. 2009;35(2):103-14.

25. Srinivasan V, Singh J, Pandi-Perumal SR, Brown GM, Spence DW, Cardinali DP. Jet lag, circadian rhythm sleep disturbances, and depression: the role of melatonin and its analogs. Adv Ther. 2010;27(11):796-813.

26. Tec L. Depression and jet lag. Am J Psychiatry. 1981;138(6):858.

27. Jauhar P, Weller MP. Psychiatric morbidity and time zone changes: a study of patients from Heathrow airport. Br J Psychiatry. 1982;140:231-5.

28. Boulos Z, Macchi MM, Stürchler MP, Stewart KT, Brainard GC, Suhner A, et al. Light visor treatment for jet lag after westward travel across six time zones. Aviat Space Environ Med. 2002;73(10):953-63.

29. Young DM. Psychiatric morbidity in travelers to Honolulu, Hawaii. Compr Psychiatry. 1995;36(3):224-8.

30. Oyewumi LK. Jet lag and relapse of schizoaffective psychosis despite maintenance clozapine treatment. $\mathrm{Br} \mathrm{J}$ Psychiatry. 1998;173:268.

31. Vanden Bogaerde A, De Raedt R. Cognitive vulnerability in fear of flying: the role of anxiety sensitivity. Depress Anxiety. 2008;25(9):768-73.

32. McCarthy GW, Craig KD. Flying therapy for flying phobia. Aviat Space Environ Med. 1995;66(12):1179-84.

33. Walder CP, McCracken JS, Herbert M, James PT, Brewitt N. Psychological intervention in civilian flying phobia. Evaluation and a three-year follow-up. Br J Psychiatry. 1987;151:494-8.

34. Trimmel M, Burger M, Langer G, Trimmel K. Treatment of fear of flying: behavioral, subjective, and cardiovascular effects. Aviat Space Environ Med. 2014;85(5):550-62.

35. Ss

36. Daly RJ, Aitken RC, Rosenthal SV. Flying phobia: phobia: phenomenological study. Proc R Soc Med. 1970;63(9):878-82.

37. Cárdenas G, Botella C, Quero S, Moreyra L, De La Rosa A, Muñoz S A Cross-Cultural Validation of VR Treatment System for Flying Phobia in the Mexican Population. Stud Health Technol Inform. 2009; 144:141-4.

38. Ahn JC, Lee O. Alleviating travel anxiety through virtual reality and narrated video technology. Bratisl Lek Listy. 2013;114(10):595602.

39. Rothbaum BO, Hodges LF, Kooper R, Opdyke D, Williford JS, North M. Effectiveness of computer-generated (virtual reality) graded exposure in the treatment of acrophobia. Am J Psychiatry. 1995;152(4):626-8
40. Botella C, Baños RM, Perpiñá C, Villa H, Alcañiz M, Rey A. Virtual reality treatment of claustrophobia: a case report. Behav Res Ther. 1998;36(2):239-46.

41. Wald J, Taylor S. Efficacy of virtual reality exposure therapy to treat driving phobia: a case report. J Behav Ther Exp Psychiatry. 2000;31(3-4):249-57.

42. Richard A, Klein P. Virtual reality exposure therapy in the treatment of fear of flying. Journal of Contemporary Psychotherapy. 2000;2:195-210.

43. Wallach HS1, Bar-Zvi M. Virtual-reality-assisted treatment of flight phobia. Isr J Psychiatry Relat Sci. 2007:44(1):29-32.

44. Eslami P, Monshi G, Haj Ebrahimi Z. Effectiveness of virtual reality therapy to reduce fear of flying in people with fear of flying. Journal of Clinical Psychology. 2013;13(4):43-61. Persian

45. Brenda K, Wiederhold MSA, Richard G, Mark D, Wiederhold MD. Fear of flying: A case report using virtual reality therapy with physiological monitoring. Cyberpsychology and Behavior. 1998;(1)2:77:97-102.

46. Rothbaum BO, Hodges L, Anderson PL, Price L, Smith S. Twelvemonth follow-up of virtual reality and standard exposure therapies for the fear of flying. J Consult Clin Psychol. 2002;70(2):428-32.

47. Kaplan A. Virtual reality exposure therapy effective for patients with specific phobias. Psychiatric Times. 2000;17:123-5.

48. Beckham JC, Vrana SR, May JG, Gustafson DJ, Smith GR. Emotional processing and fear measurement synchrony as indicators of treatment outcome in fear of flying. J Behav Ther Exp Psychiatry. 1990;21(3):153-62.

49. Waterhouse J, Reilly T, Atkinson G, Edwards B. Jet lag: trends and coping strategies. Lancet. 2007;369(9567):1117-29.

50. Reilly T, Waterhouse J, Edwards B. Jet lag and air travel: implications for performance. Clin Sports Med. 2005;24(2):367-80, xii

51. Sack RL. The pathophysiology of jet lag. Travel Med Infect Dis. 2009;7(2):102-10.

52. Oxenkrug GF, Requintina PJ. Melatonin and jet lag syndrome: experimental model and clinical implications. CNS Spectr. $2003 ; 8(2): 139-48$

53. Katz G, Durst R, Zislin Y, Barel Y, Knobler HY. Psychiatric aspects of jet lag: review and hypothesis. Med Hypotheses. 2001;56(1):203.

54. Forbes-Robertson S, Dudley E, Vadgama P, Cook C, Drawer S, Kilduff L. Circadian disruption and remedial interventions: effects and interventions for jet lag for athletic peak performance.Sports Med. 2012;42(3):185-208.

55. Auger RR, Morgenthaler TI. Jet lag and other sleep disorders relevant to the traveler. Travel Med Infect Dis. 2009;7(2):60-8

56. Ariznavarreta C, Cardinali DP, Villanúa MA, Granados B, Martín $\mathrm{M}$, Chiesa JJ, and et al. Circadian rhythms in airline pilots submitted to long-haul transmeridian flights. Aviat Space Environ Med. 2002;73(5):445-55.

57. Manfredini R, Manfredini F, Fersini C, Conconi F. Circadian rhythms, athletic performance, and jet lag. Br J Sports Med. 1998;32(2):101-6.

58. Zisapel N. Circadian rhythm sleep disorders: pathophysiology and potential approaches to management. CNS Drugs. 2001;15(4):31128.

59. Reilly T, Waterhouse J, Edwards B. Some chronobiological and physiological problems associated with long-distance journeys. Travel Med Infect Dis. 2009;7(2):88-101.

60. Coste O, Lagarde D, Coste O, Lagarde D. Travel Med Infect Dis. Clinical management of jet lag: what can be proposed when performance is critical? 2009;7(2):82-7.

61. Boulos Z, Macchi MM, Stürchler MP, Stewart KT, Brainard GC, Suhner A, and et al. Light visor treatment for jet lag after westward travel across six time zones. Aviat Space Environ Med. 2002;73(10):953-63.

62. Vosko AM, Colwell CS, Avidan AY. Jet lag syndrome: circadian organization, pathophysiology, and management strategies. Nat Sci Sleep. 2010;2:187-98

63. Reynolds NC Jr, Montgomery R. Using the Argonne diet in jet lag prevention: deployment of troops across nine time zones. Mil Med. 2002;167(6):451-3.

64. Srinivasan V, Singh J, Pandi-Perumal SR, Brown GM, Spence DW, Cardinali DP. Jet lag, circadian rhythm sleep disturbances, and depression: the role of melatonin and its analogs. Adv Ther. 2010;27(11):796-813. 